\title{
BEBERAPA ASPEK EKOLOGI, POPULASI POHON, DAN PERMUDAAN ALAM TUMBUHAN PENGHASIL GAHARU KELOMPOK KARAS (Aquilaria spp.) DI WILAYAH PROVINSI JAMBI \\ (Some Ecological Aspect, Tree Population, and Natural Regeneration of Agarwood Tree of Karas Groups (Aquilaria spp.) in Jambi Province Region)*)
}

\author{
Oleh/By: \\ Yana Sumarna \\ Pusat Litbang Hutan dan Konservasi Alam \\ Jl. Gunung Batu No. 5 Po Box 165; Telp. 0251-8633234, 7520067; Fax 0251-8638111 Bogor
}

*) Diterima : 27 Desember 2007; Disetujui : 24 Maret 2008

\begin{abstract}
Indonesia has the highest resources potency of the agarwood tree producer in the world. Naturally they grow at various condition of ecosystem and forest type. At the beginning people collected agarwood from the died tree, but due to the increased demand in the market and naturally selling price turned higher, people started hunting and cutting living tree. This activity endangers the agarwood natural population. Since year 2004, the genus of Aquilaria spp. and Gyrinops sp. have been put in the Appendix II CITES (Convention on International Trade on Endangered Species of Wild Flora and Fauna). In order to support the conservation effort, ecological study of agarwood tree producer is needed. The research was conducted through field survey in 3 sites namely site at $<100 \mathrm{~m}, 200 \mathrm{~m}$, and $>200 \mathrm{~m}$ above sea level. Each observation was replicated 3 times. The location of the study was in Tabir Ulu subdistrict on Sorolangun regency on Jambi Province. The results showed that air temperature range from $20-33^{\circ} \mathrm{C}$, humidity range from $78-81 \%$, light intensity range from 56-75\% with rainfall range from 1,200-1,500 mm/year. Tree Aquilaria spp. population in forest area according to altitude mean only 7 tree, the population potency of seedling nature average from each mother tree of the Aquilaria malaccensis Lamk mean amount to 287 seedling (20,3 $\mathrm{m}^{2}$ crown canopy) and for the type Aquilaria microcarpa Bail amount to 331 seedling (24,5 $\mathrm{m}^{2}$ crown canopy).
\end{abstract}

Key words : Karas, agarwood, ecologically, ecology, plantation

\begin{abstract}
ABSTRAK
Indonesia memiliki potensi sumberdaya pohon penghasil gaharu tertinggi di dunia, secara biologis tumbuh pada berbagai kondisi ekosistem serta tipe hutan. Gaharu semula diperoleh masyarakat dengan cara memungut dari pohon penghasil yang telah mati alami. Akibat berkembangnya nilai guna dan tingginya permintaan pasar dengan harga jual tinggi, kini masyarakat memburu gaharu dengan cara menebang pohon hidup yang telah mengancam kelestarian populasi sumberdaya. Komisi CITES (Convention on International Trade on Endangered Species of Wild Flora and Fauna), sejak tahun 2004 telah menetapkan genus Aquilaria spp. dan Gyrinops sp. masuk dalam Appendix II CITES. Dalam upaya konservasi dan pembudidayaan pohon penghasil gaharu, secara biologis perlu memperhatikan aspek parameter ekologis tempat tumbuh. Untuk mendukung keberhasilan tumbuh dalam budidaya, dasar teknis akan ditentukan oleh parameter ekologis tempat tumbuh. Penelitian yang dilakukan melalui metode survey dalam tiga blok pengamatan sesuai ketinggian di atas permukaan laut $(<100 \mathrm{~m}, 200 \mathrm{~m},>200 \mathrm{~m}$ ) yang diulang tiga kali yang dilakukan di wilayah hutan Kecamatan Tabir Ulu, Kabupaten Merangin, Provinsi Jambi. Diperoleh data parameter ekologis berupa suhu udara nisbi berada antara $20-33^{\circ} \mathrm{C}$, kelembaban nisbi antara $78-81 \%$, intensitas cahaya antara $56-75 \%$ dengan curah hujan wilayah antara 1.200-1.500 mm/th. Populasi pohon Aquilaria spp. dalam kawasan hutan sesuai ketinggian tempat tumbuh rata-rata hanya 7 batang per satuan kelompok sebaran ketinggian tempat tumbuh, sedang potensi populasi permudaan alam pada setiap pohon induk untuk jenis Aquilaria malaccensis Lamk rata-rata sebanyak 287 batang (luas tajuk 20,3 $\mathrm{m}^{2}$ ) dan untuk jenis Aquilaria microcarpa Bail sebanyak 331 batang (luas tajuk 24,5 $\mathrm{m}^{2}$ ).
\end{abstract}

Kata kunci : Karas, gaharu, sebaran tumbuh, ekologi, budidaya 


\section{PENDAHULUAN}

Indonesia dengan letak geografis serta dukungan musim, iklim serta masa penyinaran matahari yang panjang, secara biologis memiliki peluang tumbuh dan berkembangnya sumberdaya tumbuhan yang tinggi, sehingga dikenal sebagai negara mega biodiversitas kedua setelah Brazilia (Manan, 1998). Heyne (1987) melaporkan bahwa dalam kawasan hutan selain ditemukan sumberdaya tumbuhan berpotensi sebagai penghasil kayu, juga dapat dijumpai beragam jenis tumbuhan hasil hutan bukan kayu (HHBK) yang tinggi. Salah satu produk HHBK yang berpotensi dan bernilai komersial tinggi adalah komoditi gaharu (Badan Litbang Kehutanan, 2006).

Gaharu dalam perdagangan internasional dikenal dengan nama dagang agarwood, aloewood, atau eaglewood telah dikenal masyarakat Indonesia sejak tahun 1200 dan menjadi salah satu mata dagang barter antara masyarakat Sumatera Selatan dan Kalimantan Barat dengan masyarakat Kwang Tung, China (Biro KLN dan Investasi, 2002).

Produksi gaharu merupakan hasil hutan alami yang dipungut dan dikumpulkan masyarakat dari pohon yang telah mati dan memiliki bentuk produk berupa gumpalan, serpihan, dan bubuk (Sumarna, 2002). Santoso (1986) melaporkan bahwa gaharu terbentuk sebagai akibat pohon terinfeksi oleh penyakit dari kelompok cendawan (fungi). Secara biologis penyakit masuk melalui luka patahan cabang yang selanjutnya akan mengonsumsi energi hara dari sel-sel pada jaringan kayu yang pada akhirnya pohon akan mati dan dalam kayu akan terbentuk damar wangi (resin) yang bila terbakar (fumigasi) akan menghasilkan aroma keharuman yang khas. Akibat intensitas pemungutan tinggi dan pola produksi yang kurang tepat, potensi produksi gaharu Indonesia dari tahun ke tahun cenderung terus menurun. Pada akhir tahun 1990 ekspor gaharu Indonesia dapat mencapai lebih dari 600 ton per tahun dan hingga tahun 2000 dengan kuota ekspor 300 ton hanya dapat dipenuhi antara 10-15\% (Salampesi, 2004). Biro Pusat Statistik (2006) melaporkan bahwa pada tahun 2000 kuota ekspor gaharu Indonesia antara 50-150 ton, akibat terjadinya penurunan produksi hingga tahun 2004 tidak tercatat adanya data ekspor gaharu ke pasar internasional. Menurunnya produksi diduga kuat oleh akibat tingginya intensitas pemungutan dan perubahan pola produksi yang berdampak terhadap menurunnya populasi pohon penghasil.

Sumarna (2002), Sidiyasa dan Suharti (1998), Gun et al. (2004) melaporkan bahwa tumbuhan penghasil gaharu berasal dari famili Thymeleaceae, Euphorbiaceae, dan Leguminoceae dengan delapan genus yakni Aquilaria sp., Aertoxylon sp., Enkleia sp., Gonystylus sp., Gyrinops sp., Wikstroemia sp., Exccocaria sp., dan Dalbergia sp. Untuk sementara di Indonesia dapat dijumpai sebanyak 27 jenis. Penyebaran tempat tumbuh pohon penghasil gaharu relatif luas dan hampir dapat dijumpai pada berbagai kondisi wilayah dan tipe hutan, baik di Jawa, Sumatera, Kalimantan, Sulawesi, Maluku, Nusa Tenggara, maupun Papua.

Berkembangnya ilmu pengetahuan dan teknologi industri pada saat ini, gaharu tidak saja dibutuhkan sebagai bahan parfum, kosmetik, dan aroma terapi, juga dibutuhkan sebagai bahan obat herbal untuk pengobatan stress, rematik, radang ginjal dan lambung, antibiotik TBC, kanker dan tumor serta malaria (Materia Medica China dalam Sumarna dan Santoso, 2006). Gun et al. (2004) menyatakan dalam upaya mempertahankan kelestarian sumberdaya tumbuhan penghasil gaharu, Convention on International Trade on Endangered Species of Wild Flora and Fauna (CITES) sejak tahun 2004 telah menetapkan kelompok genus Aquilaria spp. dan Gyrinops sp. sebagai tumbuhan dalam Appendix II CITES.

Salah satu aspek dasar dalam melaksanakan budidaya jenis tumbuhan penghasil gaharu, keberhasilan tumbuh akan 
ditentukan oleh aspek parameter ekologis tempat tumbuh. Sedangkan aspek teknik silvikultur pengadaan bahan tanaman, selain dapat dikembangkan dengan benih juga secara teknis dapat dibina dengan memanfaatkan potensi anakan alam tingkat semai (Sumarna, 2002).

Berdasarkan beberapa asumsi di atas, dilaksanakan penelitian dengan tujuan untuk mendapatkan informasi tentang parameter ekologis dan potensi permudaan alam pohon penghasil gaharu di wilayah Provinsi Jambi. Hasil pengamatan ini diharapkan dapat menjadi dasar dalam menetapkan lahan serta upaya teknis dalam pengadaan bahan tanaman dengan memanfaatkan permudaan alam untuk mendukung upaya pengembangan budidaya.

\section{METODOLOGI}

\section{A. Lokasi dan Waktu Penelitian}

\section{Risalah Lokasi}

Lokasi pengamatan ekologis dan potensi tumbuhan penghasil gaharu, secara administratif pemerintahan masuk wilayah Kecamatan Tabir Ulu, Kabupaten Merangin, Provinsi Jambi. Topografi kawasan hutan memiliki ketinggian antara 50-600 m dpl, tergolong hutan dataran rendah dan perbukitan. Vegetasi hutan tergolong sebagai hutan sekunder yang dihuni oleh kelompok tumbuhan famili Dipterocarpaceae dari jenis-jenis meranti (Shorea sp.) dan Dipterocarpus sp. Hidrologi kawasan hutan dipengaruhi oleh daerah aliran sungai utama yakni Sungai Manau yang membelah sebagian besar kawasan dengan tiga anak sungai.

\section{Waktu}

Pelaksanaan pengamatan ekologis, potensi jenis, dan permudaan alam, dilaksanakan pada bulan Agustus 2005.

\section{B. Bahan dan Alat Penelitian}

1. Peta kawasan hutan produksi skala 1: 100.000 di wilayah Kabupaten Merangin (Bangko-Sorolangun), Provinsi Jambi.
2. Alat ukur ketinggian (altimeter), suhu dan kelembaban (thermohygrometer), intensitas cahaya (lightmeter), dan alat bantu penghitung permudaan alam (cheqcounter).

3. Perlengkapan untuk membuat spesimen herbarium.

\section{Metode}

Sesuai dinamika sebaran tumbuh pohon penghasil gaharu yang berkelompok, maka metode pola pengamatan ekologis dan potensi pohon dan permudaan alam dilaksanakan secara Blok Area (blocking areas) dengan pembatas tiga faktor ketinggian di atas permukaan laut (dpl) : $<100$ m, 200 m, dan >200 m dpl. Dari setiap faktor ketinggian diamati parameter ekologi meliputi: (a) suhu, (b) kelembaban, dan (c) intensitas cahaya. Sesuai faktor distribusi daerah ketinggian, dipilih secara acak tiga pohon induk untuk diamati potensi populasi permudaan alam dalam tiga ulangan dengan sampel plot tingkat seedling (sd) luasan satu $\mathrm{m}^{2}$ dari luas tajuk dalam dan tingkat sampling (sp) pada luasan dua $\mathrm{m}^{2}$. Untuk mendapatkan data dugaan potensi permudaan alam, dapat dihitung melalui perkalian rata-rata populasi permudaan alam dengan luas tajuk rata-rata pohon induk dari tiga ulangan sesuai kelas diameter batang pohon induk.

\section{HASIL DAN PEMBAHASAN}

\section{A. Hasil}

\section{Parameter Ekologi}

Hasil pengamatan terhadap faktor ekologi tempat tumbuh sesuai daerah sebaran pohon induk berdasarkan ketinggian di atas permukaan laut (altitude), diperoleh nilai rata-rata kondisi suhu pada ketinggian sampai dengan ketinggian $100 \mathrm{~m}: 27^{\circ} \mathrm{C}$, kelembaban nisbi sekitar $78 \%$, dan intensitas cahaya sekitar $75 \%$. Pada ketinggian $200 \mathrm{~m}$, suhu udara ratarata sekitar $24^{\circ} \mathrm{C}$, kelembaban sekitar $83 \%$, dan intensitas cahaya sekitar $67 \%$, 
sedangkan pada daerah ketinggian $>200$ $\mathrm{m}$, suhu udara $20^{\circ} \mathrm{C}$, kelembaban sekitar $81 \%$ dengan intensitas cahaya masuk sekitar 56\% (Tabel 1).

\section{Potensi Tingkat Pohon dan Permudaan Alam}

Potensi tegakan tingkat pohon penghasil gaharu dari genus Aquilaria pada tiga kelompok daerah sebaran tumbuh, sesuai ketinggian di atas permukaan laut sebanyak 64 pohon atau memiliki rata- rata 21,3 pohon (Tabel 2). Pada kawasan hutan dijumpai dua jenis pohon penghasil gaharu dari jenis Aquilaria malaccensis Lamk dan Aquilaria microcarpa Baill dengan masing-masing jenis pada setiap pohon induk memiliki potensi rata-rata permudaan alam tingkat semai dan pancang, untuk jenis $A$. malaccensis berjumlah 287 batang dengan luas tajuk rata-rata 20,3 $\mathrm{m}^{2}$, dan untuk jenis $A$. microcarpa sebanyak 331 batang pada luas tajuk rata-rata 24,5 $\mathrm{m}^{2}$ (Tabel 3 dan Tabel 4).

Tabel (Table) 1. Rataan kondisi parameter ekologi lingkungan tempat tumbuh pada strata ketinggian dan waktu pengamatan pagi, siang, dan sore (Average microclimate parameter of the study site)

\begin{tabular}{|c|c|c|c|c|c|c|c|c|c|}
\hline \multirow{3}{*}{ Waktu (Time) } & \multicolumn{9}{|c|}{ Ketinggian (Altitude ) (m) } \\
\hline & \multicolumn{3}{|c|}{$<100$} & \multicolumn{3}{|c|}{200} & \multicolumn{3}{|c|}{$>200$} \\
\hline & $\begin{array}{l}\text { Suhu } \\
\left({ }^{\circ} \mathrm{C}\right)\end{array}$ & $\begin{array}{l}\mathrm{Rh} \\
(\%)\end{array}$ & $\begin{array}{c}\text { Cahaya } \\
(\%)\end{array}$ & $\begin{array}{l}\text { Suhu } \\
\left({ }^{\circ} \mathrm{C}\right)\end{array}$ & $\begin{array}{l}\mathrm{Rh} \\
(\%)\end{array}$ & $\begin{array}{c}\text { Cahaya } \\
(\%)\end{array}$ & $\begin{array}{l}\text { Suhu } \\
\left({ }^{\circ} \mathrm{C}\right)\end{array}$ & $\begin{array}{l}\mathrm{Rh} \\
(\%)\end{array}$ & $\begin{array}{c}\text { Cahaya } \\
(\%)\end{array}$ \\
\hline Pagi (Morning) & 20 & 77,60 & 70,04 & 20 & 82,20 & 67,80 & 20 & 81,05 & 54,20 \\
\hline Siang (Daying) & 33 & 79,02 & 75,80 & 27 & 79,60 & 67,80 & 31 & 80,14 & 59,80 \\
\hline Sore (Evening) & 28 & 77,80 & 80,00 & 26 & 83,20 & 67,20 & 29 & 82,40 & 54,20 \\
\hline
\end{tabular}

Keterangan (Remark) : Waktu pengamatan (Observation time) : pagi (morning) 7.00-9.00; siang (daying) 12.00-14.00), sore (evening) 15.00-16.00

Tabel (Table) 2. Potensi tingkat pohon gaharu genus Aquilaria sp. (Potency of agarwood tree of Aquilaria sp.)

\begin{tabular}{|c|c|c|c|c|c|}
\hline \multirow{2}{*}{ Ulangan (Replication) } & \multicolumn{3}{|c|}{ Ketinggian (Altitude) } & \multirow{2}{*}{$\begin{array}{c}\text { Jumlah } \\
\text { (Total) }\end{array}$} & \multirow{2}{*}{$\begin{array}{l}\text { Rata-rata } \\
\text { (Average) }\end{array}$} \\
\hline & $(<100 \mathrm{~m})$ & $(200 \mathrm{~m})$ & $(>200 \mathrm{~m})$ & & \\
\hline $\mathrm{I}$ & 3 & 7 & 11 & 21 & 7,0 \\
\hline II & 6 & 8 & 10 & 24 & 8,0 \\
\hline III & 4 & 6 & 9 & 19 & 6,3 \\
\hline Jumlah (Total) & 13 & 21 & 30 & 64 & 21,3 \\
\hline Rata-rata (Average) & 4,3 & 7 & 10 & 21,3 & 7,0 \\
\hline
\end{tabular}

Tabel (Table) 3. Potensi permudaan alam jenis A. malaccensis (Natural regeneration potency of A. malaccensis)

\begin{tabular}{ccccccccc}
\hline \multirow{2}{*}{ Ulangan (Replication) $)$} & \multicolumn{2}{c}{$\mathrm{T}_{1}(<100 \mathrm{~m})$} & \multicolumn{2}{c}{$\mathrm{T}_{2}(200 \mathrm{~m})$} & \multicolumn{2}{c}{$\mathrm{T}_{3}(>200 \mathrm{~m})$} & Jumlah \\
\cline { 2 - 7 } & $\mathrm{Sd}$ & $\mathrm{Sp}$ & $\mathrm{Sd}$ & $\mathrm{Sp}$ & $\mathrm{Sd}$ & $\mathrm{Sp}$ & (Total) \\
\hline I & 252 & 25 & 216 & 49 & 250 & 28 & 910 \\
II & 175 & 40 & 286 & 55 & 311 & 37 & 894 \\
III & 232 & 35 & 230 & 46 & 306 & 24 & 873 \\
Jumlah (Total) & 659 & 100 & 732 & 140 & 867 & 89 & 2.587 \\
Rata-rata (Average) & 220 & 33 & 244 & 47 & 289 & 30 & 287 \\
\hline
\end{tabular}

Keterangan (Remark) : Sd : Seedling, Sp : Sapling 
Tabel (Table) 4. Potensi permudaan alam jenis A. microcarpa (Natural regeneration potency of A. microcarpa)

\begin{tabular}{|c|c|c|c|c|c|c|c|}
\hline \multirow{2}{*}{ Ulangan (Replication) } & \multicolumn{2}{|c|}{$\mathrm{T}_{1}(<100 \mathrm{~m})$} & \multicolumn{2}{|c|}{$\mathrm{T}_{2}(200 \mathrm{~m})$} & \multicolumn{2}{|c|}{$\mathrm{T}_{3}(>200 \mathrm{~m})$} & \multirow{2}{*}{$\begin{array}{l}\text { Jumlah } \\
\text { (Total) }\end{array}$} \\
\hline & Sd & $\mathrm{Sp}$ & $\mathrm{Sd}$ & Sp & Sd & Sp & \\
\hline I & 272 & 45 & 272 & 86 & 300 & 45 & 1.020 \\
\hline II & 225 & 49 & 267 & 89 & 49 & 283 & 962 \\
\hline III & 282 & 45 & 267 & 62 & 292 & 38 & 996 \\
\hline Jumlah (Total) & 779 & 139 & 806 & 247 & 875 & 132 & 2.978 \\
\hline Rata-rata (Average) & 260 & 46 & 269 & 82 & 292 & 44 & 331 \\
\hline
\end{tabular}

Keterangan (Remark) : Sd : Seedling, Sp : Sapling

\section{B. Pembahasan}

Secara umum dengan nilai parameter ekologis suhu, kelembaban, dan intensitas cahaya yang diamati sesuai strata ketinggian di atas permukaan laut $(<100 \mathrm{~m}$, $200 \mathrm{~m},>200 \mathrm{~m}$ ) diperoleh data suhu udara nisbi sekitar $20-33^{\circ} \mathrm{C}$, kelembaban nisbi antara $78-81 \%$, dan intensitas cahaya 56-75. Pada kondisi ekologis dengan parameter tersebut secara biologis kondisi kawasan hutan masih tergolong cukup baik dan terpelihara optimal yang ditunjukkan oleh masih tingginya keragaman populasi tumbuhan hutan. Kramer dan Kozlowski (1979) melaporkan bahwa tumbuhan dalam kawasan hutan secara biologis akan sangat dipengaruhi oleh optimalnya faktor ekologis berupa suhu yang akan berpengaruh terhadap proses metabolisme serta daya permeabilitas dan viskositas kerja sel-sel organ tumbuhan. Kelembaban secara fisiologis akan berpengaruh terhadap aspek penyerapan hara yang erat kaitannya dengan besaran curah hujan. Sedangkan besaran intensitas energi cahaya yang masuk ke lantai hutan akan berperan terhadap sistem metabolisme dan proses fotosintesa serta besaran respirasi dalam menghasilkan energi perkembangan tumbuhnya pohon (Larcher, 1975). Fitter dan Hay (1992) melaporkan bahwa kebutuhan parameter suhu pada tumbuhan tinggi ada pada kisaran $10-60^{\circ}$ $\mathrm{C}$, pada kondisi optimum akan berperan dalam mempengaruhi proses biokimia serta sistem kerja enzim, sedangkan kondisi kelembaban erat kaitannya dengan tata air (curah hujan) yang erat hubungannya dengan tekanan turgor pada sel-sel tanaman yang menghasilkan peran terhadap proses pembelahan sel (mitosis). Parameter intensitas cahaya secara fisiologis akan berperan sebagai sumber energi yang akan diserap oleh daun dalam mengolah hara lahan melalui proses fotosintesa untuk menghasilkan energi pertumbuhan dan perkembangan tanaman. Sesuai data parameter ekologis yang diamati, secara biologis kawasan hutan di wilayah Kabupaten Merangin relatif masih cukup baik bagi upaya pembinaan dan pengembangan berbagai jenis tumbuhan hutan, termasuk upaya budidaya pohon penghasil gaharu.

Memperhatikan populasi pohon penghasil gaharu, baik jenis A. malaccensis maupun jenis $A$. microcarpa yang relatif tumbuh berkelompok dengan jumlah yang terbatas, sesuai laporan masyarakat hingga tahun 1998 banyak pandatang dari Sumatera Barat dan Riau mencari gaharu dengan cara menebang pohon hidup dan mencacah batang untuk mencari bagian kayu yang telah bergaharu. Berdasarkan asumsi keberadaan kedua jenis pohon penghasil gaharu yang terdapat dalam kawasan hutan, maka secara ideal pemilihan jenis untuk dibudidayakan adalah jenis A. malaccensis atau A. microcarpa, karena merupakan tumbuhan insitu yang tumbuh pada habitatnya (endemik) dan secara ekologis sudah memenuhi kesesuaian tumbuh pada wilayah setempat. Untuk pembudidayaan dalam jangka pendek pohon induk alami (seed stand), tersedianya bahan tanaman dapat dilakukan dengan memanfaatkan potensi benih dan atau permudaan alam. Sumarna (2002) melaporkan bahwa secara biologis bahan tanaman gaharu dapat dikembang- 
kan dengan memanfaatkan potensi benih dan permudaan alam yang tumbuh di bawah tegakan pohon induk. Sesuai hasil pengamatan potensi permudaan alam yang tumbuh di bawah pohon induk, untuk jenis $A$. malaccensis rata-rata sebanyak 287 batang per satuan pohon induk dengan rata-rata luas tajuk $20,3 \mathrm{~m}^{2}$ dan untuk jenis $A$. microcarpa rata-rata sebanyak 331 batang pada rata-rata luas tajuk 24,5 $\mathrm{m}^{2}$, maka secara biologis kawasan hutan di wilayah Merangin potensi tingkat pohon yang dapat berperan sebagai pohon induk masih cukup potensial sebagai sumber bahan tanaman dalam mendukung upaya konservasi jenis dan pengembangan budidaya. Dalam setiap satuan pohon induk alami, secara biologis potensi benih yang jatuh pada selang umur setelah tiga bulan akan menghasilkan tumbuhnya permudaan alam dengan populasi yang tinggi, tetapi akibat persaingan hara dan lingkungan tumbuh, populasi akan menurun (Sumarna, 2004). Sumarna dan Santoso (2006) melaporkan bahwa pengadaan bahan tanaman pohon penghasil gaharu dengan memanfaatkan potensi benih/buah dan permudaan alam, perlu mengetahui dan memperhatikan aspek fenologi masa berbunga dan kondisi masak buah. Untuk memanfaatkan benih sebagai bahan tanaman, di bawah pohon induk perlu dipersiapkan jaring sebagai alat penampung benih, sedang upaya pemanfaatan permudaan alam secara ideal pada lahan di bawah tegakan pohon induk perlu dibersihkan, diolah, dan diberi perlakuan pemberian pupuk organik. Untuk mendapatkan bibit dari anakan alam yang baik, secara teknis perlu diketahui ukuran cabutan anakan alam yang tepat agar diperoleh bibit yang baik dan berkualitas.

\section{KESIMPULAN DAN SARAN}

\section{A. Kesimpulan}

1. Potensi sumberdaya pohon penghasil gaharu semakin menurun sebagai dampak negatif dari perubahan pola produksi yaitu dilakukan dengan cara menebang pohon hidup.

2. Parameter ekologis tempat tumbuh berupa suhu, kelembaban, dan besaran intensitas cahaya yang masuk ke lantai hutan cukup optimal dan dapat menjadi dasar untuk menentukan aspek kesesuaian tumbuh dalam upaya pembudidayaan pohon penghasil gaharu.

3. Jenis Aquilaria malaccensis Lamk dan A. microcarpa Baill yang dijumpai tumbuh endemis dapat ditetapkan dan dipelihara sebagai pohon induk alami (seeds stand) dalam mendukung upaya pembudidayaan bagi wilayah Kabupten Merangin.

\section{B. Saran}

1. Konservasi jenis sumberdaya pohon penghasil gaharu perlu dilakukan melalui upaya pembudidayaan, karena sebagai sumber kehidupan masyarakat sekitar hutan.

2. Upaya pengembangan budidaya pada lahan bukan daerah asal jenis (exsitu), parameter suhu, kelembaban dan intensitas cahaya yang teramati, dapat dijadikan dasar dalam upaya menetapkan kondisi lahan budidaya tanaman penghasil gaharu.

3. Tegakan pohon induk Aquilaria malaccensis Lamk dan A. microcarpa Baill yang ada perlu dipelihara dan dijaga sebagai pohon induk sumber bahan tanaman (bibit).

4. Potensi permudaan alam yang tumbuh di bawah tegakan pohon induk alami (seeds stand) dapat dimanfaatkan sebagai tanaman.

\section{DAFTAR PUSTAKA}

Badan Litbang Kehutanan. 2006. Teknologi Budidaya, Pemanfaatan dan Pengembangan Hasil Hutan Bukan Kayu. Pusat Penelitian dan Pengembangan Hasil Hutan. Bogor. 
Biro KLN dan Investasi. 2002. Menjual Kayu dalam Gram. Sekretariat Jenderal Departemen Kehutanan. Jakarta.

Biro Pusat Statistik. 2006. Data Ekspor Perdagangan Hasil Hutan. Departemen Perindustrian dan Perdagangan. Jakarta.

Fitter, A.H. dan R.K.M. Hay. 1992. Physiology Lingkungan Tanaman (Terjemahan). Gajah Mada University Press.Yogyakarta.

Gun, B., P. Steven, M. Singadan, L. Sunari, P. Chatterton. 2003. Eaglewood in Papua New Guinea. Tropical Rain Forest Project. Working Paper No. 51. Vietnam.

Heyne, K. 1987. Tumbuhan Berguna Indonesia Jilid I s/d IV. Badan Litbang Kehutanan. Jakarta.

Kramer, P.J. dan T.T. Kozlowski. 1979. Physiology of Woody Plant. University of Durhan, University of Wisconsin, Academic Press Inc. London.

Larcher, W. 1975. Physiological Plant Ecology. University Innsbruck, London.

Manan, S. 1998. Hutan Rimbawan dan Masyarakat. IPB Press. Bogor.
Salampesi, F. 2004. Tata Niaga Perdagangan Gaharu di Indonesia. Prosiding Lokakarya Budidaya dan Pengembangan Komoditi Gaharu. Direktorat Jenderal Rehabilitasi Lahan dan Perhutanan Sosial. Jakarta.

Santoso, E. 1986. Pembentukan Gaharu dengan Cara Inokulasi. Prosiding Diskusi Hasil Penelitian Menunjang Pemanfaatan Hutan Lestari. Pusat Litbang Hutan dan Konservasi Alam. Bogor.

Sidiyasa, K. dan S. Suharti. 1998. Potensi Jenis Pohon Penghasil Gaharu. Prosiding Lokakarya Pengembangan Tanaman Gaharu. Direktorat Jenderal Rehabilitasi Lahan dan Perhutanan Sosial. Jakarta.

Sumarna, Y. dan E. Santoso. 2006. Teknologi Budidaya dan Rekayasa Produksi Gaharu. Gelar Teknologi Badan Litbang Kehutanan. Jakarta.

Sumarna, Y. 2002. Budidaya Gaharu. Seri Agribisnis. Penebar Swadaya. Jakarta.

Sumarna, Y. 2004. Budidaya dan Rekayasa Produksi Gaharu. Sosialisasi Mikoriza, Gaharu, dan Cuka Kayu. Biro Kerjasama Luar Negeri. Jakarta. 